\title{
Long Term Examination of the Profitability Estimation Focused on Benefits
}

\author{
Stephan Printz, Kristina Lahl, René Vossen, Sabina Jeschke
}

\begin{abstract}
Strategic investment decisions are characterized by high innovation potential and long-term effects on the competitiveness of enterprises. Due to the uncertainty and risks involved in this complex decision making process, the need arises for well-structured support activities. A method that considers cost and the long-term added value is the cost-benefit effectiveness estimation. One of those methods is the "profitability estimation focused on benefits - PEFB"-method developed at the Institute of Management Cybernetics at RWTH Aachen University. The method copes with the challenges associated with strategic investment decisions by integrating long-term non-monetary aspects whilst also mapping the chronological sequence of an investment within the organization's target system. Thus, this method is characterized as a holistic approach for the evaluation of costs and benefits of an investment. This participation-oriented method was applied to business environments in many workshops. The results of the workshops are a library of more than 96 cost aspects, as well as 122 benefit aspects. These aspects are preprocessed and comparatively analyzed with regards to their alignment to a series of risk levels. For the first time, an accumulation and a distribution of cost and benefit aspects regarding their impact and probability of occurrence are given. The results give evidence that the PEFB-method combines precise measures of financial accounting with the incorporation of benefits. Finally, the results constitute the basics for using information technology and data science for decision support when applying within the PEFB-method.
\end{abstract}

Keywords - Cost-benefit analysis, multi-criteria decision, profitability estimation focused on benefits, risk and uncertainty analysis.

\section{INTRODUCTION}

$\mathrm{S}$ TRATEGIC investment decisions (SID) are defined as "substantial investments that involve high levels of risk, produce hard-to-quantify (or intangible) outcomes and have a significant long term impact on corporate performance [1]." Hence, the process of strategic decision making (SDM) has emerged as an important research field over the past decade [2].

Controlling the complexity and uncertainty surrounding

Stephan Printz is scientific assistant at the Institute for Management Cybernetics e.V. at RWTH Aachen University, Aachen, 52068 Germany (corresponding author; phone: +49 24180911 84; fax: +49 24180911 22; email: stephan.printz@ifu.rwth-aachen.de).

Kristina Lahl is research group leader of the Institute for Management Cybernetics e.V. at RWTH Aachen University, Aachen, 52068 Germany (email:kristina.lahl@ifu.rwth-aachen.de).

René Vossen is division manager of the Institute for Management Cybernetics e.V. at RWTH Aachen University, Aachen, 52068 Germany (email: rene.vossen@ifu.rwth-aachen.de).

Sabina Jeschke is the director of the institute cluster IMA/ZLW \& IfU at RWTH Aachen University, Aachen, 52068 Germany (e-mail: sabina.jeschke@ima-zlw-ifu.rwth-aachen.de).
SID presents particular challenges for the management [3]. In addition, SID have an effect on the whole competitiveness of the organization [4], [5]. For this reason, efficient information search and evaluations are necessary [6]. The evaluation of accounting for SID has to pay more attention to scenariobased techniques [7], [8].

Field studies give evidence that traditional profitability analysis assessing SID is supplanted by sophisticated techniques in terms of linking qualitative and (quantitative) financial aspects [1], [9]-[11]. While the quantification and assignment of cost is examined extensively, there are fewer methods for the assignment of long-term benefits [12]. In fact, the evaluation of utilizing quantitative and qualitative criteria in decision making is a challenge when implementing effective decisions [13]. However, involving teams in the decision making process (DMP) improves the quality of the decision [14] and allows for alternative evaluations in the problem solving process [15]. Hence, much of the DMP in companies is decided as a team [16], [17].

The PEFB-method [18], [19] faces challenges with SID. However, since its development there has been no evaluation of the method itself regarding its applicability. Hence, a review of requirements and a comparative analysis of the gathered cost and benefit aspects are required. With these results, the applicability of the PEFB-method is confirmed and the baseline for future research is set up.

\section{STATE OF THE ART}

Research has aimed to answer the questions surrounding which analyses are being used to assess SID [20]. In fact, financial accounting information assists managers to give a quantitative overview of the current company situation and prepare for future decisions [21]. Hence, SID are usually based on economic criteria, often without considering qualitative issues [22]. Even if qualitative criteria is incorporated in the SID, there is a lack of structured and validated methodologies [23], [24]. However, scientists argue that an organization's philosophy itself and organizational context vary across circumstantial settings [25], [26].

The DMP is characterized by different attitudes and different knowledge of uncertainties arising as a result of imprecisions and vagueness of information [27]. In particular, SDM is involved with questions affecting the long-term success of the company, the allocation of significant resources and the trade-off in ambiguous situations as a result of insufficient information [28], [29].

In general, involving teams in decision making (DM) improves the solution quality and generates a wider variety of 
problem solutions [17]. The DM can be supported by group decision making frameworks. Most of the proposed methodology frameworks within the business environment are related to mathematical decision support frameworks [30], [31]. These frameworks are related to Analytical Hierarchy Processes [27] and Fuzzy preference relations [32], [33]. However, the implementation of mathematical models needs experienced customers and sometimes fails due to a lack of skills and its complexity [30], [34]. As a result of these uncertainties and the limitations of skills and abilities, there is a search for new management approaches [3]. The requirements of the new approach are summarized in Table I. This method should provide accuracy of financial accounting decisions (R1) through the incorporation of qualitative criteria (R2). The SID has to be performed in a structured series of steps and provide valid results. In particular, so as to prioritize the sequence of investment, a timeline is required (R3). Furthermore, the treatment of insufficient information and information quality has to be integrated (R4). Finally, the method has to be non-complex and easy to use so as to reduce time and effort expenditure (R5). Finally, the approach has to integrate research and evaluations by financial experts, just like all experts affected within the company (R6).
TABLE I

REQUIREMENTS FOR NEW SID APPROACH

\begin{tabular}{cc}
\hline \hline Requirement $[R]$ & Description of the requirement \\
\hline R1 & Precise measure of financial accounting \\
R2 & Incorporation of qualitative criteria \\
R3 & Structured and valid methodology \\
R4 & Treating of insufficient information \\
R5 & No remarkable skills to use required \\
R6 & Team decision \\
\hline \hline
\end{tabular}

\section{THE PEFB-METHOD}

The PEFB-method is a participation-oriented, cybernetic approach for the evaluation of a SID. Based upon the utility analysis and the profitability analysis of IT-investment [19], [35], [36] both measurable monetary factors and nonmonetary aspects are considered and thus requirements (R2) and (R6) are met. Fig. 1 shows an overview of the PEFBmethod according to the problem solving process [37]. Hence, the PEFB-method meets the demands of (R3). Moreover, to perform the method, no remarkable skills are required (R5). To demonstrate compliance with the given evidence, a short description of the PEFB-method is shown below. Examination of the requirements of (R1) and (R4) is part of the research design and a realization of the long-term evaluation.

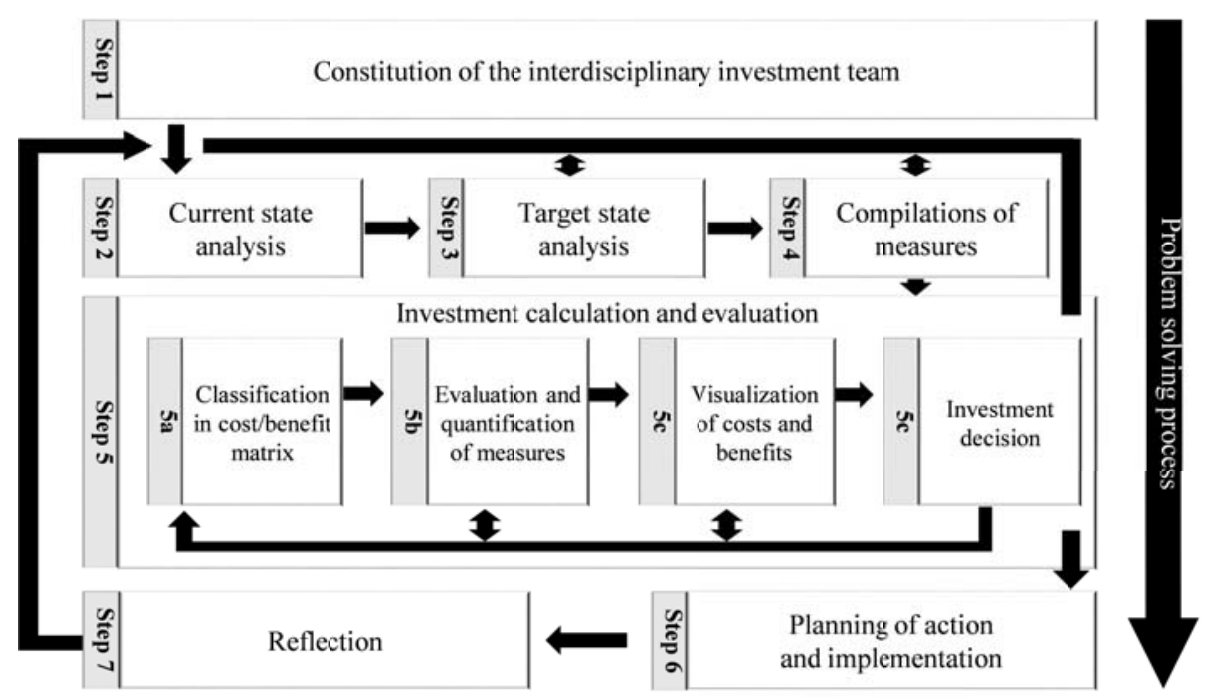

Fig. 1 Steps of the PEFB-method

The following description shows the stages of the PEFBmethod [38]. The PEFB-methods consists of seven steps:

1. Constitution of the interdisciplinary investment team,

2. Current situation analysis,

3. Target situation analysis,

4. Compilation of measures,

5. Investment evaluation,

6. Planning of actions and

7. Reflection.

Step 1 consists of building a representative interdisciplinary investment team containing executives and employees involved and affected. Hence, not only are the concerned departments represented, but also the various levels of hierarchy. This team will be responsible for conducting the evaluation, implementation and reflection process.

By building up an interdisciplinary investment team and through the support of a facilitator, a holistic view on the SID is ensured. Within the current state analysis (step 2), skills and competencies inside the enterprise are identified. Furthermore, by means of the target state analysis (step 3), the strategically, tactical and operational objectives of the project are identified and noted on a specification sheet. Step 4 involves a compilation of concrete measures so as to achieve the target level of enterprise.

In step 5, the investment calculation and evaluation is carried out through 4 sub tasks. It encompasses the 
classification of costs and benefits, the evaluation and quantification of measures, visualization of cost and benefits as well as the investment decision. The method uses two different portfolios for the classification of costs and benefits (cf. Table II, cf. Table III). Costs and benefits of the investment are defined and assigned in terms of their impact on the project as "direct", "indirect" or "difficult to ascertain" aspects.

Direct costs or benefits are those, which are related to the investment and enable the impact to be measured directly, e.g. acquisition costs or increase of productivity. Accordingly, indirect costs or benefits are a derivate from direct effects, for instance maintenance costs or increased quality. Finally, "difficult to ascertain" costs or benefits contain effects which can only be presumed, like demotivation of employees or improving the image of the company. Moreover, the measures are classified regarding their probabilities of occurrence into the classes high, medium, and low.

TABLE II

COST-PORTFOLIO

\begin{tabular}{cccc}
\multicolumn{4}{c}{ Cost-PorTFOLIO } \\
\hline \hline & High & Medium & Low \\
\cline { 2 - 5 } Direct & $\mathbf{9}$ & $\mathbf{7}$ & $\mathbf{4}$ \\
Indirect & $\mathbf{8}$ & $\mathbf{5}$ & $\mathbf{2}$ \\
Difficult to ascertain & $\mathbf{6}$ & $\mathbf{3}$ & $\mathbf{1}$ \\
\hline \hline
\end{tabular}

Corresponding to the introduced impact classes, the measures are assigned in a $3 \times 3$-matrix. Each cell of the matrix contains a so called risk level, reaching from 1 to 9 . The two portfolios differ in the arrangement of the risk level. Meanwhile, direct costs with high probability are assigned to the risk level 9 (cf. Table II), benefit risk levels are designated contrarily. Direct benefits with high probability of occurrence refer to risk level 1 (cf. Table III).

TABLE III BENEFIT-PORTFOLIO

\begin{tabular}{cccc}
\hline \hline & High & Medium & Low \\
\cline { 2 - 4 } Direct & $\mathbf{1}$ & $\mathbf{3}$ & $\mathbf{6}$ \\
Indirect & $\mathbf{2}$ & $\mathbf{5}$ & $\mathbf{8}$ \\
Difficult to ascertain & $\mathbf{4}$ & $\mathbf{7}$ & $\mathbf{9}$ \\
\hline \hline
\end{tabular}

Within the framework of visualization, the levels define a ranking scale of measures. After the classification and quantification of the aspects, the filled cells of the matrix are aligned in two numerical series. The overall costs $\left(\mathrm{C}_{\mathrm{m}}\right)$ for each risk level (j) are calculated from the individual cost aspects $\left(c_{j}\right)$ (refer to (1)). The modality for the computation of the overall benefits $\left(B_{n}\right)$ each benefit $\left(b_{j}\right)$ is done similarly (see (2)).

$$
\begin{gathered}
C_{m}=\sum_{j=1}^{(9-m)+1} c_{j} \\
B_{n}=\sum_{j=1}^{9} b_{j}
\end{gathered}
$$

The value of each risk level is recorded in a risk oriented PEFB-chart (see Fig. 2). In relation to the possible intersection situations, four general cases can be distinguished. On the one hand, when the cost function is beneath the benefit function in all nine levels, the investment is economically evaluated as recommendable without restrictions. On the other hand, if the cost function is always above the benefit function, the investment is evaluated as definitely uneconomical. Finally, in the case of an intersection of both curves, an interpretation of the risk level is required.

Investment scenarios with an intersection of both graphs in risk level 1 are the most economically reasonable. In terms of the descriptive interpretation, the overall costs are exceeded by direct and highly probable benefits. Contrarily, the worst economically reasonable investment scenario is at the location of the intersection point at the risk level 9. In this intersection point, direct and highly probable costs exceed all possible benefits.

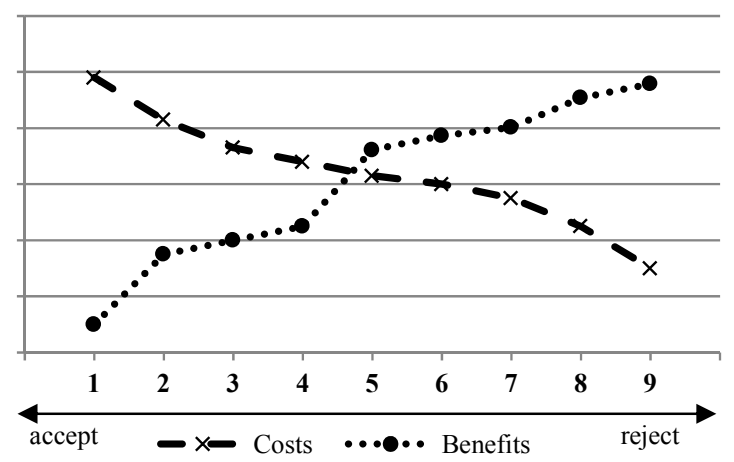

Fig. 2 PEFB-chart

In step 6, the next stage of the investment decision is determined. Depending on the results, this step relates to whether a plan of action or plan implementation is necessary. In particular, the advice regarding the evaluation of strategies is directly incorporated into the transfer process. Finally, the interdisciplinary investment team appraises the experiences gathered during the process (step 7). Accordingly, in the reflection phase a review of the whole investment evaluation process is carried out and appropriate recommendations are made. However, there is need to prove the compliance of the PEFB-method with (R1) and (R4). Thus, further research with regard to the fulfillment of the requirements is needed.

\section{RESEARCH DESIGN}

The PEFB-method was applied in research projects as well as industrial projects. To evaluate the method's compliance with the precise measure of financial accounting (R1) and the treatment of insufficient information (R4), a chronological overview is shown in Table IV. Due to non-disclosure agreements, only the results of 14 independent workshops are allowed to be used for public evaluation. Besides the 14 applied PEFB-methods introduced over the last 10 years, the date of application and a short description of the assessed subject are given. In addition, a categorization of the projects is also provided. The categories display the areas of assessment divided into technology and methodology evaluation. 
Among the 14 displayed application fields, 7 belong to the category of technology assessment, whereas 4 projects belong to the methodology assessment. In 3 cases a mixture of the methodology approach and a launch of a new technology were assessed. During the application of the PEFB-method, more than 96 costs aspects and 122 benefits were acquired. Due to inconsistencies within specific aspects, there is a need for data processing.

TABLE IV

APPLIED AREAS OF THE PEFB-METHOD

\begin{tabular}{|c|c|c|c|}
\hline \multirow{2}{*}{ Year } & \multirow{2}{*}{ Project description } & \multicolumn{2}{|c|}{ Area of assessment } \\
\hline & & Technology & Methodology \\
\hline 2006 & Launch of a data processing service & $\mathrm{X}$ & $\mathrm{X}$ \\
\hline 2006 & IT outsourcing solutions & $\mathrm{X}$ & \\
\hline 2006 & Construction of a parking garage & & $\mathrm{X}$ \\
\hline 2008 & Semantic-based knowledge flow system for the European home textiles industry & $\mathrm{X}$ & $\mathrm{X}$ \\
\hline 2011 & Intelligent Mega-Swap-Boxes for Advanced Intermodal Freight Transport & $\mathrm{X}$ & \\
\hline 2012 & Lead-User method for innovation search & & $\mathrm{X}$ \\
\hline 2012 & Broadcast Search for innovations & & $\mathrm{X}$ \\
\hline 2012 & Ideas competition for innovation search & & $\mathrm{X}$ \\
\hline 2012 & Safety technology for firefighters & $\mathrm{X}$ & \\
\hline 2013 & Mass produced textile preforms by automated handling and online quality assurance & $\mathrm{X}$ & \\
\hline 2013 & IT-support during the development of engineering standardization & $\mathrm{X}$ & $\mathrm{X}$ \\
\hline 2014 & Online quality assurance for hot edge/hot air welding & $\mathrm{X}$ & \\
\hline 2014 & Intelligent Transport System for Innovative Intermodal Freight Transport & $\mathrm{X}$ & \\
\hline 2015 & Automation of Tricot machines & $X$ & \\
\hline
\end{tabular}

In order to perform a baseline study of correlating data, aspects aligned into different impact classes were excluded. If aspects are aligned within the same impact class, but dedicated to other probabilities of occurrence, they were adapted manually. These aspects are marked in the cost and benefit library. The adaption was performed either by majority or the lower risk level. Due to non-total order of the different risk levels the average risk level is not calculated.

\section{A. Cost Aspects}

Regarding these different types of applications, more than 96 different cost aspects were gathered. Among those, 13 aspects were inconsistent within their aligned impact classes. Hence, these values were canceled for the evaluation. Moreover, 5 aspects were adapted manually (marked). Table $\mathrm{V}$ gives an overview of the remaining 83 cost aspects in their original terms. Besides the aspects itself, the number of nomination $[\mathrm{n}]$ is illustrated just like the risk level.

The total number of the aggregated costs aspects is 125 , thus the average number of cost aspects for one PEFBapplication is 8.93. Besides some common aspects like capital costs, the reduction of staff, or the demotivation of the employees, most of the aspects are individual for each project. The average number of nomination is 1.51 . The distribution of all cost aspects within the impact classes are presented in Fig. 3.

The impact class of direct costs has a share of $57.83 \%$. This impact class consists of $75.00 \%$ of high probability costs (risk level 9). This makes up the majority in this class followed by medium probabilities of $18.75 \%$ (risk level 7). In the end direct costs with low probability gain a share of $6.25 \%$ (risk level 4). Compared to impact class of direct costs, indirect costs have an overall share of $25.30 \%$. The class consists of a share $38.10 \%$ for high probability costs (risk level 8), 33.33\% for medium costs (risk level 5) and $28.57 \%$ for low probabilities (risk levels 2).

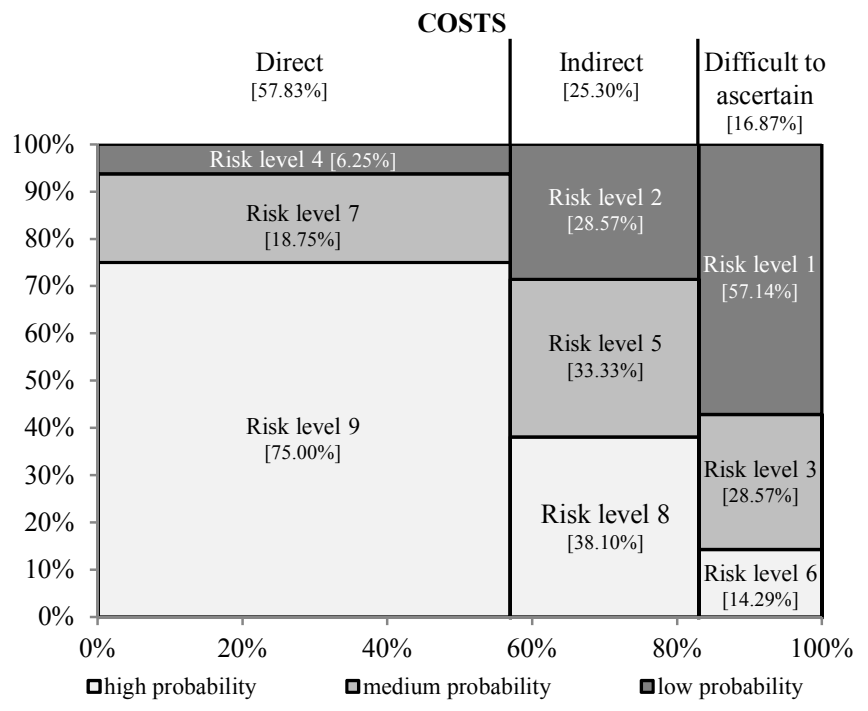

Fig. 3 Marimekko chart of the cost aspect distribution

In particular, the impact class of difficult to ascertain costs has a share of $16.87 \%$. The majority within this impact class is formed by low probabilities with a share of $57.14 \%$ (risk level 1). Meanwhile, medium probabilities have a share of $28.57 \%$ (risk level 3). Finally, high probabilities (risk level 6) gain a share of $14.29 \%$.

\section{B. Benefit Aspects}

In addition, the preparation of the benefit aspects was done in the same way. By data adjustment, 30 benefit aspects with inconsistent impact class alignments were deleted from the overall number of 122 benefit aspects. The remaining 92 
benefit aspects are shown in Table VI. The 6 benefit aspects which are manually adjusted are marked.

TABLE V

LIBRARY OF COST ASPECTS

\begin{tabular}{|c|c|c|}
\hline Cost aspects & Number [n] & Risk level \\
\hline Aboriginal costs & 1 & 9 \\
\hline Acceptance by machine operator & 1 & 1 \\
\hline Additional charges to ensure IT-security while using IT-based standardization & 1 & 5 \\
\hline Adoption of the vehicles (GPS) & 1 & 9 \\
\hline Annual granting costs & 1 & 9 \\
\hline Assembly & 2 & 8 \\
\hline Bad declaration of performance relationships & 1 & 8 \\
\hline Bought-in parts & 1 & 9 \\
\hline Calibration of the equipment & 1 & 4 \\
\hline Capital costs & 3 & 1 \\
\hline Changeover costs & 1 & 1 \\
\hline Choice of suitable intermediary & 1 & 9 \\
\hline Communication effort with solver & 1 & 9 \\
\hline Contract costs & 2 & 9 \\
\hline Contract negotiation & 1 & 9 \\
\hline Costs for sample picture creation & 1 & 9 \\
\hline Debriefing costs & 1 & 5 \\
\hline Demotivation & 4 & 1 \\
\hline Denoting trucks & 1 & 9 \\
\hline Destination charges & 3 & 8 \\
\hline Developing a standard & 1 & 5 \\
\hline Development of IT-platform & 1 & 9 \\
\hline Development prototype & 1 & 7 \\
\hline Digitalization of samples & 1 & 9 \\
\hline Editing workshop results & 1 & 9 \\
\hline Empty running & 1 & 1 \\
\hline Expenses for data utilization (customer) & 1 & 8 \\
\hline Finance costs & 3 & 9 \\
\hline Flexibility boundary & 1 & 4 \\
\hline Flexibility for Just in time & 1 & 3 \\
\hline Formulating a problem & 3 & 9 \\
\hline Formulation of tender & 1 & 9 \\
\hline Garment (jackets, gloves) & 1 & 9 \\
\hline Handling and washing procedure for equipment & 1 & 9 \\
\hline Hardware costs & 1 & 9 \\
\hline Helmet (camera + vision, communication device) & 1 & 9 \\
\hline Hidden costs (generous conditions at contract closing / high debts at later change requests) & 1 & 2 \\
\hline High sill, height of chassis and cam distance & 1 & 2 \\
\hline Higher risk of injuries & 2 & 1 \\
\hline Higher risk of know-how theft through intensive exchange with potential competitors & 3 & 3 \\
\hline Higher risk of standardization employee's distraction & 1 & 1 \\
\hline Higher space requirement & 1 & 9 \\
\hline Higher system complexity & 1 & 9 \\
\hline Image loss & 3 & 3 \\
\hline Insurance for the technical equipment & 1 & 7 \\
\hline Integration existing equipment & 1 & 9 \\
\hline Investment costs & 4 & 9 \\
\hline Lead-User identification und recruitment & 1 & 9 \\
\hline Legal conflict & 3 & 2 \\
\hline Legal counsel & 3 & 9 \\
\hline Less control & 1 & 6 \\
\hline Less flexibility (backload) & 1 & 5 \\
\hline Less staff & 8 & 8 \\
\hline License software & 2 & 9 \\
\hline
\end{tabular}




\begin{tabular}{|c|c|c|}
\hline Cost aspects & Number [n] & Risk level \\
\hline Limited service offer by contractor & 1 & 2 \\
\hline Low Sill & 2 & 1 \\
\hline Maintenance by users & 1 & 8 \\
\hline More staff & 2 & 7 \\
\hline New specialist jobs & 1 & 8 \\
\hline No accurate service provision by the outsourcing contractor & 1 & 3 \\
\hline Oncosts through downtime and maintenance time & 2 & 5 \\
\hline Premium & 2 & 9 \\
\hline Production & 2 & 5 \\
\hline Provide culture for acceptance of external knowledge & 3 & 5 \\
\hline Psychological context monitoring & 1 & 9 \\
\hline Recalls for fixing issues & 1 & 2 \\
\hline Recurrent expenses through supplier change & 1 & 4 \\
\hline Re-using the equipment & 1 & 8 \\
\hline Rewarding lead-users & 1 & 7 \\
\hline Run workshop & 1 & 9 \\
\hline Sensors & 1 & 9 \\
\hline Service & 2 & 7 \\
\hline Service provision & 1 & 9 \\
\hline Set-up time & 1 & 7 \\
\hline Shuttle costs per year & 1 & 7 \\
\hline Shuttle trains leasing costs per year & 1 & 7 \\
\hline Smart Life Line & 1 & 9 \\
\hline Spare parts & 1 & 2 \\
\hline Starting up maintenance & 1 & 6 \\
\hline Supply of data & 1 & 9 \\
\hline Terminal costs when driver changes & 1 & 7 \\
\hline Trend analysis & 1 & 9 \\
\hline Work of the expert jury & 2 & 9 \\
\hline
\end{tabular}

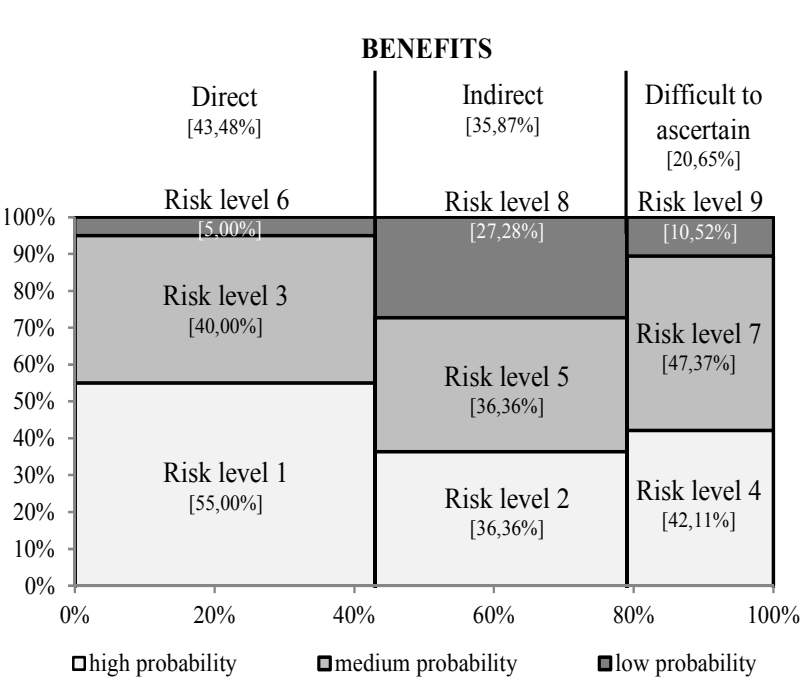

Fig. 4 Marimekko chart of the benefit aspect distribution

Collectively, the total number of aggregated benefit aspects is 131. Like the cost aspects, most of the benefit aspects are mentioned once, thus the average number of nominations is 1.42. The overall average number of benefits aspects for one application is 9.36. Common benefit aspects are, e.g. documentation, image gain or increased flexibility through implementation of technology.

In contrast to the cost aspect distribution, the allocation of the benefit matrix is shown in Fig. 4 . The direct benefits gain a share of $43.48 \%$. Within the impact class, high probability benefits (risk level 1) have a share of $55.00 \%$ followed by $40.00 \%$ with medium probability (risk level 3). Direct benefits with a low probability of occurrence have a share of $5.00 \%$ (risk level 6). With respect to the impact class of indirect benefits the share of $35.87 \%$, consist of $36.36 \%$ for high probability aspects (risk level 2 ) as well as $36.36 \%$ of medium probability aspects (risk level 5). Aspects with low probabilities have a share of $27.28 \%$ (risk level 8). On top of that, the impact class of difficult to ascertain benefits has an overall share of $20.65 \%$. The proportion within the impact class consists of $42.11 \%$ for high probabilities (risk level 4 ), $47.37 \%$ for medium probabilities (risk level 7) and $10.52 \%$ for low probabilities.

\section{V.DISCUSSION OF THE RESULTS}

The distribution of high probability cost aspects decreases throughout the impact classes (cf. Fig. 3). In contrast, the share of low probability aspects increases with the opportunity to use qualitative aspects. Based on this fact, the increasing uncertainty among the impact classes leads to a risk-averse assessment. Furthermore, the share of the impact classes decreases from direct costs to costs that are difficult to ascertain. One possible reason for the major share of direct costs might stem from an accounting department. 
TABLE VI

LIBRARY OF BENEFIT ASPECTS

\begin{tabular}{c}
\hline \hline Benefit aspects \\
\hline Acceptance by Employee \\
Amortization period \\
Availability secured \\
Basis for argumentation \\
Better control of action by team leader \\
Better procurement conditions \\
Better selling effect on Point of sale \\
Better view over entire situation \\
Central headquarters \\
Constructing production line \\
Contest's participation rate as competitions indicator \\
Cost reduction Supply Chain Management \\
Cross-linkage of convoy with headquarters \\
Deal closure \\
Decrease damage on equipment
\end{tabular}

Decrease number of and damages on victims

Decrease of dependency on single employees with specialist know-how

Digital ordering pricing Documentation

Door opening conception

Driver as dispatcher

Early error detection

Early involvement in the creation of standards

Ease of internal changes, reorganization, fusions/takeovers

Economies of scale on contractor's side causing lower prices

Efficiency increases

Employees receive inspiration

Error management

Fees

Focus on core business, core competency Grasp Frange

Higher arctic truck height through gooseneck

Higher machine workload

Idea goes into new product

Image gain / improvement

Increase of employee satisfaction

Increase of professionalism (no more self-made solutions)

Increased acceptance of respective standardization

Increased customer identification

Increased efficiency/success rate of rescue/intervention missions

Increased flexibility

Increased willingness to pay

Innovations through maintenance and updates

Inspiration for solving similar problems Insurance possible

Integration / Interface coverage

inter-company networking of experts

Inter-functionality of equipment Learning aptitude

Less controls of incoming goods

Less damage by hail, birds, trees etc.

Less risks for accidents on rail

Less room costs

Less substandard goods

\section{Number Risk}

[n] level

14

3

18

$1 \quad 1$

17

13

13

1

15

16

15

31

18

23

12

12

1

(20)

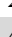

1

1

1

1

1

1

1

2

2

1

3

1

2

2

2

2

1

4

1

1
1

1
1

1

1

1

1

1

1

1

1

1

1

2

\begin{tabular}{|c|c|c|}
\hline Benefit aspects & $\begin{array}{c}\text { Number } \\
{[n]}\end{array}$ & $\begin{array}{l}\text { Risk } \\
\text { level } \\
\end{array}$ \\
\hline Less trucks on road & 1 & 4 \\
\hline Loading height & 3 & 1 \\
\hline Lower transport costs & 6 & 1 \\
\hline Maintenance on demand & 1 & 3 \\
\hline Marketing tool & 3 & 7 \\
\hline Mechanic lifting device & 1 & 2 \\
\hline More flexible Network & 1 & 7 \\
\hline Multilayer field of application & 1 & 5 \\
\hline New product & 1 & 1 \\
\hline Newest level of data security & 1 & 5 \\
\hline No IT-worries, no time exposure & 1 & 2 \\
\hline One open side & 1 & 1 \\
\hline Only one basic material & 1 & 5 \\
\hline Potential through interdisciplinary approach & 2 & 2 \\
\hline Process Reliability & 2 & 1 \\
\hline Production working capital & 1 & 8 \\
\hline $\begin{array}{c}\text { Productivity gain of already active standardization } \\
\text { employees }\end{array}$ & 1 & 1 \\
\hline Productivity gain of new standardization employees & 1 & 1 \\
\hline Qualified consulting through outsourcing contractor & 1 & 2 \\
\hline $\begin{array}{l}\text { Quality of contact increases with higher number of } \\
\text { participants }\end{array}$ & 1 & 7 \\
\hline Real life experience of sample & 2 & 3 \\
\hline Reduction of market analysis lost & 1 & 3 \\
\hline Reduction of sample cost & 1 & 3 \\
\hline Reduction of stock cost & 1 & 3 \\
\hline Reduction of working capital & 1 & 3 \\
\hline Reduction stock cost & 1 & 8 \\
\hline Vehicle conditioning & 1 & 5 \\
\hline Risk of oil price increase & 1 & 3 \\
\hline Road taxes independency & 1 & 2 \\
\hline Saving of development work & 2 & 1 \\
\hline Savings by low insurance & 2 & 5 \\
\hline Support in tactical decisions & 1 & 4 \\
\hline $\begin{array}{c}\text { Tactical support for resource management at scene of } \\
\text { accident }\end{array}$ & 1 & 4 \\
\hline Tailgate & 1 & 2 \\
\hline Total benefits & 1 & 1 \\
\hline Transfer of debts to contractor & 1 & 3 \\
\hline Tri-Modal & 3 & 1 \\
\hline Vehicle store place & 1 & 1 \\
\hline
\end{tabular}

In particular, a share of $75.00 \%$ for risk level 9 and $18.75 \%$ for risk level 7 represents the precise recording of these cost factors. Analyzing the impact class of indirect costs (25.30\%) highlights a change in the distribution of probability share. All probabilities roughly gain a share of around $30.00 \%$. This result represents the transitional period from the quantitative to the qualitative aspects, where cost aspects are not easily provided by the accounting department. Despite that, difficult to ascertain costs gain a share of $16.87 \%$. Actually, this result provides evidence for literary research by describing that cost estimation could be done precisely by accounting departments. Interpretation of the benefit evaluation clearly shows that the relevant requirement is met, including long-term effects on SID Thus, the PEFB-method meets the demand of the precise measure of financial accounting (R1). In contrast, the benefit aspects differ in their share of impact classes and probabilities (cf. Fig. 4). The share of the direct impact class of benefits is 
around $14 \%$ lower than the share of the direct costs. Indeed, the share of the indirect impact class increases around 13\% compared to costs. With a difference of nearly $4 \%$, the impact class of difficult to ascertain benefits is in a similar situation to the costs class. For every class there is a significant difference regarding the distribution of the probabilities of occurrence within the impact classes. Moreover, there is an increase in the share of all probabilities in the impact class of difficult to ascertain aspects. It is likely therefore that this constitutes to the fact that benefits in comparison to costs are surrounded by more uncertainty within the evaluated projects. The benefit distribution reveals that a resolution of insufficient information is ensured (R4).

The overall purpose of the PEFB-method is to gain knowledge regarding the investment decision. Due to reflecting potential impacts, future development becomes more certain. With respect to the challenge of SID, the use of the different impact classes represents qualitative aspects just like quantitative aspects. Hence, the results of the overall distribution of cost and benefit aspects are different.

Regarding the impact of cost and benefit distribution, Fig. 5 shows the relative frequency of the introduced cost and benefit aspects in the PEFB-chart. A sample of one assessed project reveals that the average value of the cost and benefit aspects fluctuates at around $+/-10 \%$, hence, the representation of the qualitative analysis is possible. The general intersection point of the evaluated projects is stated at the risk level 3.92 .

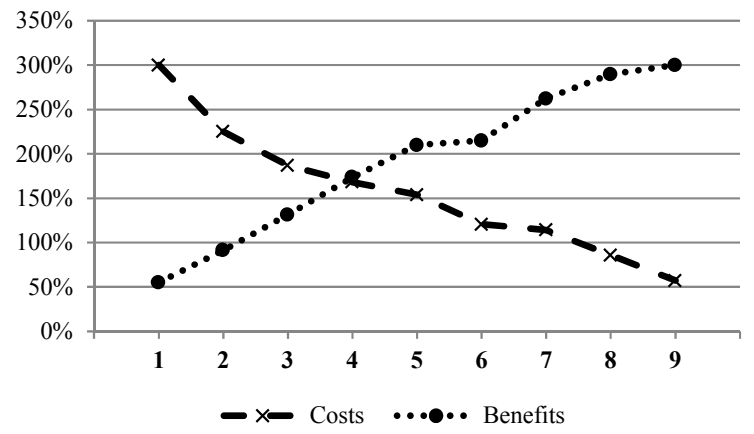

Fig. 5 Relative frequency of cost and benefits aspects in the PEFBchart

According to the classification of the risk portfolio, there are two interpretations. The SID depends on the probability of benefits with high probability of occurrence and direct benefits with medium probability of occurrence. Indeed, SID are functions from which it is particularly difficult to ascertain benefit aspects with a high probability of occurrence (risk level 4). Secondly, the run of the cost curve illustrates the SID to be a function of all costs aspects with high probability of occurrence just like direct and indirect cost aspects with medium probability of occurrence.

In general, the comparative analysis indicates that the PEFB-method is able to provide a precise measure of cost accounting besides the compilation of long-term effects. Hence, the PEFB-method could be stated as one possible method to assess SID. However, the presented evaluation is only one step to refine the PEFB-method. The purpose is to define a catalogue with aggregated cost and benefit aspects with predefined risk levels. Therefore, the company has to choose the aspect itself and put it in the organizational context.

Referring to the results of the conducted study, it is possible to illustrate for the first time the relationship between benefit and cost aspects as a function of temporal sequences. The results illustrate the importance of indirect benefits in decision making processes. However, these aspects are surrounded by uncertainty, thus there is a need for more information. Modern information technology provides approaches like data science, predictive analysis and big data methods to gather more information. The combination of a participation oriented decision making process and data science is an interesting field of research for the advancement of the PEFB method.

\section{FUTURE RESEARCH}

In general, progresses in information technology and participation oriented methods need to be linked to future research. Especially, methods of information search like data science are becoming promising approaches increasing information quality and the validity of SID. In order to use data science for information search within the PEFB-method, a methodology to assess information quality has to be developed. The challenge is to identify information sources and their ranking. In addition, future research based upon this evaluation should focus on several aspects. In particular, the visualization of the PEFB-results needs a refining. The interpretation of the intersection point gives no statement regarding profitability. Hence, the challenge is to combine visualization of the results and a sensitivity analysis of the quantified aspects. Moreover, the evaluation of the risk level alignment, the distribution of the quantified aspects and real monetary values should be evaluated, too. In addition, a review of the success rate of implemented technologies or applied methodologies is required.

With regard to the correlating data preparation, 43 aspects were excluded from the evaluation because of inconsistency in the alignment into impact classes. The split of the excluded data is 13 cost aspects and 30 benefit aspects. In fact, the number of benefits is more than 2.3 times higher than the elimination rate of the cost aspects. Hence, the examination of these aspects and the reason for the inconsistency is required.

A promising approach to explain the inconsistency might be the constitution of the interdisciplinary investment team. In particular, the role of the interdisciplinary investment team with regards to risk preference, personal affection and moderating team effects should be examined. Furthermore, the subject of the PEFB-method has to be reviewed in terms of the surrounding uncertainty expressed by the desired target situation.

\section{REFERENCES}

[1] F. Alkaraan and D. Northcott, "Strategic capital investment decisionmaking: A role for emergent analysis tools?," Br. Account. Rev., vol. 38, no. 2, pp. 149-173, 2006. 
[2] V. M. Papadakis, "Do CEOs shape the process of making strategic decisions? Evidence from Greece,” Manag. Decis., vol. 44, no. 3, pp 367-394, Mar. 2006.

[3] Gorzeń-Mitka and M. Okręglicka, "Improving Decision Making in Complexity Environment," Procedia Econ. Finance, vol. 16, pp. 402409, 2014.

[4] C. Carr and C. Tomkins, "Context, culture and the role of the finance function in strategic decisions. A comparative analysis of Britain, Germany, the U.S.A. and Japan," Manag. Account. Res., vol. 9, no. 2 , pp. 213-239, Jun. 1998.

[5] C. Carr, "Strategic investment decisions: the importance of SCM. A comparative analysis of 51 case studies in U.K., U.S. and German companies," Manag. Account. Res., vol. 7, no. 2, pp. 199-217, 1996.

[6] F. T. Rothärmel, Strategic management, Second edition. New York, NY: McGraw-Hill Education, 2015.

[7] T. M. Alessandri, D. N. Ford, D. M. Lander, K. B. Leggio, and M. Taylor, "Managing risk and uncertainty in complex capital projects," $\mathrm{Q}$. Rev. Econ. Finance, vol. 44, no. 5, pp. 751-767, Dec. 2004.

[8] K. D. Miller and H. G. Waller, "Scenarios, Real Options and Integrated Risk Management," Long Range Plann., vol. 36, no. 1, pp. 93-107, Feb. 2003.

[9] R. Slagmulder, W. Bruggeman, and L. van Wassenhove, "An empirical study of capital budgeting practices for strategic investments in CIM technologies,” PROECO Int. J. Prod. Econ., vol. 40, no. 2, pp. 121-152, 1995.

[10] R. W. Adler, "Strategic investment decision appraisal techniques: The old and the new," BUSHOR Bus. Horiz., vol. 43, no. 6, pp. 15-22, 2000.

[11] H. Siegwart and U. Singer, "Neues Verfahren für die Wirtschaftlichkeitsbeurteilung von Investitionen in neue Produktionstechnologien” Kostenrechnungspraxis Krp, vol. 2, pp. 63 70, 1991.

[12] M. Schönheit, Wirtschaftliche Prozeßgestaltung: Entwicklung Fertigung Auftragsabwicklung. Springer-Verlag, 2013.

[13] O. Itanyi, U. J. F. Ewurum, and W. I. Ukpere, "Evaluation of decision making criteria with special reference to quantitative and qualitative paradigms,” Afr. J. Bus. Manag., vol. 6, no. 44, pp. 11110-11117, 2012.

[14] P. F. Drucker, The Effective Executive: Effektivität un Handlungsfähigkeit in der Führungsrolle gewinnen. München: Vahlen, 2014.

[15] J. DuBrin: Leadership: research findings, practice, and skills. Boston: Houghton Mifflin, 2001.

[16] J. Bonito, Interaction and influence in small group decision making. 2014.

[17] O. Negulescu and E. Doval, "The Quality of Decision Making Process Related to Organizations' Effectiveness,” Procedia Econ. Finance, vol. 15 , pp. 858-863, 2014.

[18] E. Savelsberg, Innovation in European freight transportation basics, methodology and case studies for the European markets. Berlin; London: Springer, 2008

[19] D. Weydandt, Beteiligungsorientierte wirtschaftliche Bewertung von technischen Investitionen für prozessorientierte Fertigungsinseln. Aachen: Shaker, 2000.

[20] G. Sandahl and S. Sjögren, "Capital budgeting methods among Sweden's largest groups of companies. The state of the art and a comparison with earlier studies," Int. J. Prod. Econ., vol. 84, no. 1, pp 51-69, Apr. 2003.

[21] A.-D. Socea, "Managerial Decision-Making and Financial Accounting Information," Procedia - Soc. Behav. Sci., vol. 58, pp. 47-55, Oct. 2012.

[22] R. Dekkers, "Impact of strategic decision making for outsourcing on managing manufacturing,” Int. J. Oper. Prod. Manag., vol. 31, no. 9, pp. 935-965, Aug. 2011.

[23] T. Baines, "An integrated process for forming manufacturing technology acquisition decisions," Int. J. Oper. Prod. Manag., vol. 24, no. 5, pp. 447-467, May 2004

[24] G. Frank, D. V. S. de Souza, J. L. D. Ribeiro, and M. E. Echeveste, "A framework for decision-making in investment alternatives selection," Int. J. Prod. Res., vol. 51, no. 19, pp. 5866-5883, Oct. 2013.

[25] P. Miller and T. O'Leary, Capital budgeting, co-ordination and strategy: A field study of inter-firm and intra-firm mechanisms. Oxford University Press Oxford, 2005.

[26] F. H. M. Verbeeten, "Do organizations adopt sophisticated capital budgeting practices to deal with uncertainty in the investment decision?," Manag. Account. Res., vol. 17, no. 1, pp. 106-120, Mar. 2006.
[27] N. Bryson, "Group decision-making and the analytic hierarchy process: Exploring the consensus-relevant information content," Comput. Oper. Res., vol. 23, no. 1, pp. 27-35, Jan. 1996.

[28] E. Wallace and R. Rijamampianina, "Strategic decision making with corporate emotional intelligence," Probl. Perspect. Manag., vol. 3, pp. 83-91, 2005.

[29] H. Dincer, G. Gencer, N. Orhan, and K. Sahinbas, "The Significance of Emotional Intelligence on the Innovative Work Behavior of Managers as Strategic Decision-Makers," Procedia - Soc. Behav. Sci., vol. 24, pp. 909-919, 2011

[30] Kengpol and P. Boonkanit, "The decision support framework for developing Ecodesign at conceptual phase based upon ISO/TR 14062," Int. J. Prod. Econ., vol. 131, no. 1, pp. 4-14, May 2011.

[31] D. Golmohammadi and M. Mellat-Parast, "Developing a grey-based decision-making model for supplier selection," Int. J. Prod. Econ., vol. 137, no. 2, pp. 191-200, Jun. 2012.

[32] F. Herrera, L. Martínez, and P. J. Sánchez, "Managing nonhomogeneous information in group decision making," Eur. J. Oper. Res., vol. 166, no. 1, pp. 115-132, Oct. 2005.

[33] Palomares, R. M. Rodríguez, and L. Martínez, "An attitude-driven web consensus support system for heterogeneous group decision making," Expert Syst. Appl., vol. 40, no. 1, pp. 139-149, Jan. 2013.

[34] M. B. Barfod, K. B. Salling, and S. Leleur, "Composite decision support by combining cost-benefit and multi-criteria decision analysis," Decis. Support Syst., vol. 51, no. 1, pp. 167-175, Apr. 2011

[35] K. Nagel, Nutzen der Informationsverarbeitung: Methoden zur Bewertung von strategischen Wettbewerbsvorteilen, Produktivitätsverbesserungen und Kosteneinsparungen. München (u.a.): Oldenbourg, 1988.

[36] H. J. Ott, "Wirtschaftlichkeitsanalyse von EDV-Investitionen mit dem WARS-Modell am Beispiel der Einführung von CASE," Wirtschaftsinformatik, vol. 35, no. 6, pp. 522-531, 1993.

[37] R. Sell and R. Schimweg, Probleme lösen: in komplexen Zusammenhängen denken; mit 19 Tabellen. Berlin (u.a.): Springer, 2002.

[38] S. Printz, R. Vossen, and S. Jeschke, "Adaption of the profitability estimation focused on benefits due to personal affection," presented at the Workshop on Assessment methodologies - energy, mobility and other real world applications, Coimbra, to be published 2016 